\title{
Trabalhonecessário
}

Issn: 1808 - 799X

ano 13, número $20-2015$

\section{O TRABALHO DA EDUCAÇÃO}

José Barata-Moura ${ }^{1}$

\section{Resumo}

O texto apresenta inicialmente três notas introdutórias. A partir delas, é analisada a estreita e profunda relação entre a Educação e o Trabalho. Ressalta-se, também, que o trabalho, para muito além de sua forma alienada, é um permanente processo de transformação. Nesse sentido, é possível compreender a plenitude do trabalho da educação. Pretende-se evidenciar, assim, que enquanto processo de desenvolvimento, a educação é trabalho porque forma e transforma seres humanos.

Palavras-chave: Trabalho e Educação; trabalho alienado; mundo do trabalho; trabalho da educação

\section{Abstract}

The text initially presents three introductory notes. They constitute the basis for an analysis of the deep relationship between Education and Work. The text also emphasizes that work, far more than its alienated form, is a permanent (continuous) process of transformation. In this sense, it is possible to understand the plenitude of the work on education. Thus the intention is to demonstrate that, as a process of development, education is work because it forms and transforms human beings.

Key-words: Work and Education; alienated work; the work world; work on education

\footnotetext{
1 Universidade de Lisboa.

TrabalhoNecessário - www.uff.br/trabalhonecessario; Ano 13, No 20/2015.
} 


\section{Trabalhonecessário}

Issn: 1808 - 799X

ano 13, número $20-2015$

\section{§1. Intróito.}

Agradeço ao Colectivo organizador da segunda edição do INTERCRÍTICA - Intercâmbio Nacional dos Núcleos de Pesquisa em Trabalho e Educação, do Brasil -, na pessoa da Professora Sonia Maria Rummert e do Professor Ronaldo Marcos de Lima Araújo, o muito honroso convite para proferir esta conferência de abertura².

Transmito as minhas saudações académicas à Universidade Federal do Pará, prestigiado grémio que, enquanto reitor da Universidade de Lisboa, tive, há uns anos já, o grato prazer de visitar.

Reitero publicamente o meu muito obrigado a todos os Colegas, pela excelência do acolhimento e o calor da hospitalidade.

Como intróito, três pequenos apontamentos.

Primeira nota.

De ordinário, atrela-se ao rótulo solene de "conferência» o sentido espectacular de uma locução, em registo unidireccional expendida: das alturas solitárias do púlpito para os descampados (mesmo se compostos) da plateia.

Fica, desta sorte, obliterado, porém, o regime daquela interlocução que vitaliza - não apenas depois, mas durante - uma conferência.

Porque «conferência» é - numa dupla vertente entrançada - um partilhado acto de conferir:

Como entrega de um pensado que, pensando, se expressa.

2 A sessão teve lugar em Belém, no Instituto de Ciências Jurídicas da Universidade Federal do Pará, em 26 de Agosto de 2014.

TrabalhoNecessário - www.uff.br/trabalhonecessario; Ano 13, No 20/2015. 


\section{Trabalhonecessário}

Issn: 1808 - 799X

ano 13, número 20 - 2015

E como con-fronto crítico daquilo que vai sendo ouvido com aquela experiência pensada que em cada um dos auditores se acolhe, sedimenta, e agita.

Uma con-ferência é um abandono em desafio à relação.

Não escondo que, pelo meu discurso, muito gostaria de ser capaz de despertar ao exercício esta dialogicidade. Que mais não fora, para amortecer o suplício traumático de me aturarem o porte e a falação, durante uma quarentena larga de minutos.

Segunda nota.

Quanto às matérias sobre as quais a vossa pesquisa incide, não sou versado, nem quero fazer versos. Tenho por feitio a veleidade de não compensar o defeito de expertise por uns excessos velados de assaloiada «esperteza».

Dizer, portanto, que eu sou leigo - aconchega, mas não chega.

Porque o «leigo» escuta, para aprender o que não sabe.

E eu fui convidado para usar - ou abusar - da palavra. Discorrendo sobre o que não sei, para presumíveis «aprendentes» que sabem mais, e muito melhor, do que eu.

Para quem ache que a contradição é tão-só um desvario da fantasia, aqui está um exemplo palpável de como ela mora no coração da materialidade do próprio real.

E, para quem tenha pavor de admitir na cidade o contraditório, que aconteceria se eu vos confessasse que o «segredo» do ensinante reside, precisamente, em aprender a falar de coisas... que o outro sabe?

Ensinar não é estender ao ignaro como revelação um mundo que ele desconhece. É armar o outro, e armar-se com os outros, de ferramentas e de conteúdos que permitam discernir na multiplicidade dos seus patamares, enriquecer pelas voltas do exame, e, no limite, transformar, um mundo - 


\section{Trabalhonecessário}

Issn: 1808 - 799X

ano 13, número $20-2015$

assimétrico, no arcaboiço e nas vivências - de que, no entanto, se partilha o chão.

O pensar está montado sobre um viver. Que nele se reflecte, que ele acompanha, e ao qual traz perspectiva.

Pensamos o real, de dentro do real. Em des-equilíbrio - teórico, prático, afectivo - para o real.

Mesmo quando erramos e distorcemos. Mesmo quando o propósito é fugir das fricções pela ficção. Mesmo quando, pelo trabalho do ser, rompemos a carapaça dura do existente rumo à materialização de possíveis que cada existência adiante de si pro-jecta.

Não se entusiasmem no balanço. Não baixem a guarda ao vosso pensar próprio. Como Hegel gostava de dizer: «ninguém pode pensar pelo outro»3 3 .

Ademais, tudo isto não passa de umas quantas divagações de um leigo. Que - nesta, como noutras pendências - não excede as debilidades inerentes ao seu incipiente estatuto «laical».

\section{Terceira nota.}

Pela amostra, já deve ter soado a campainha do alarme de aviso.

No jeito deste meu filosofar sem-jeito, não consigo impedir-me de accionar uma estranha maquineta de pensamento que dá pelo nome sugestivo de «complicómetro».

Não é porque eu tenha uma inveterada mania de ensarilhar.

É porque a turibulada «simplicidade», parecendo mostrar «evidências», esconde (muito mais do que dá a ver). Pode reflectir, mas não tra-duz com

\footnotetext{
3 «"O meu pensar próprio" é, propriamente, um pleonasmo. Cada um tem que pensar por si; ninguém pode pensar pelo outro.» -- «"Mein eigenes Denken" ist eigentlich ein Pleonasmus. Jeder muß für sich denken; es kann keiner für den anderen denken.», Georg Wilhelm Friedrich HEGEL, Vorlesungen über die Geschichte der Philosophie, Einleitung, B, 2, a; Theorie Werkausgabe, red. Eva Moldenhauer e Karl Markus Michel, Frankfurt am Main, Suhrkamp Verlag, 1971, vol. 18, p. 80.
} 


\section{Trabalhonecessário}

Issn: 1808 - 799X

ano 13, número $20-2015$

verdade, o concreto: das determinações, dos relacionamentos, dos processos, de que o real - na sua textura, na deveniência, nas dinâmicas - se tece e entretece.

Há também quem chame a esta «com-plicação» em desenvolvimento: dialéctica.

E deste «pecado grave», que estou pronto a reconhecer, não espero absolvição. Tão-pouco, aliás, quanto dos outros.

Andemos, porém, à nossa faina.

\section{§ 2. O tabuleiro.}

Confeccionei, para a charla de hoje, como título: «o trabalho da educação».

Sai-nos da cozinha ao prato um combinado esquisito.

Porque da travessa do falar não consta: nem o tipo de instrução requerido (ou supostamente mais apropriado) para ter êxito na esfera laborista; nem o papel educativo que as labutas (no campo, na oficina, num escritório) assumem, e representam; nem as matérias formativas, e os problemas profissionais, dos agentes que fazem da actividade educacional ganha-pão.

De facto, o meu tópico não anuncia: «educação para o trabalho», não vaticina: "educação pelo trabalho», nem se debruça sobre o universo daqueles que educam na sua qualidade de membros de uma classe trabalhadora.

Trata-se de temas que integram o perímetro das buscas. E, primam, decerto, pela relevância. Mas eles ficarão, todavia, fora do nosso ângulo de abordagem.

Acresce que os próprios termos que escolhi para o meu enunciado - o trabalho da educação - parecem excluir-se reciprocamente, polarizar uma antinomia, esconder um contra-senso. 


\section{Trabalhonecessário}

Issn: 1808 - 799X

ano 13, número $20-2015$

Não é a «educação», pelo parentesco, filha dilecta do «ócio» - que, no grego antigo, se entoava $\sigma \chi 0 \lambda \eta ́$, o étimo de onde provém, por mediação do latim, o nome de «escola» (o sítio da ociosidade)?

E não é o «trabalho», por compleição, o directo contrário desse lazer inocente da infância (ou do privilégio da mandrice dos intelectuais), que, por isso

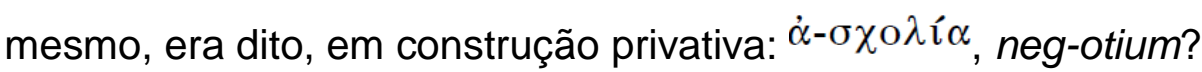

$\mathrm{Na}$ verdade, esta é uma representação dominante com impacte, um lugarcomum frequentado, uma imagem-feita que perdura.

Habitualmente, num doce vaivém entre o peremptório dogmatismo convencido da consciência errónea e o subreptício desiderato de nos incutir por insuflação algum suplemento de má-consciência, as coisas são-nos expostas e contadas assim.

E, no entanto, pode ser que elas se movam de outra maneira.

Mas, neste, como na generalidade dos casos, perguntar pelo fundamento obriga a que se enverede pela sondagem dos meandros da radicalidade. Naquele sentido preciso em que Marx lembrava - andando o lembrete, às vezes, bastante arredio da retentiva - que «ser radical é apreender a coisa na raiz» 4 .

$\mathrm{Na}$ demanda de embasamento, torna-se recomendável, portanto, descer alguns lanços na escada.

Educação e trabalho não formam mundos à parte. Porque inter-agem, no trans-formar em que ambos con-sistem. E, sobremaneira, porque fazem parte do mundo em que o humano se engendra.

Educação e trabalho integram o apresto e a manobra desse mundo. Não apenas como evanescente fenomenalidade ondulatória, na superfície. Mas como vaga de fundo, com peso, no próprio eclodir determinado daquilo que há, porque é.

4 «Radikal sein ist die Sache an der Wurzel fassen.», Karl MARX, Zur Kritik der Hegelschen Rechtsphilosophie. Einleitung (1844); Marx - Engels Gesamtausgabe, ed. Günter Heyden e Anatoli Jegorow (doravante: MEGA²), Berlin, Dietz Verlag, 1982, vol. I/2, p. 177.

TrabalhoNecessário - www.uff.br/trabalhonecessario; Ano 13, No 20/2015. 


\section{Trabalhonecessário}

Issn: 1808 - 799X

ano 13, número $20-2015$

Trabalho e educação, naqueles registos da socialidade em que comparecem, não sobrevêm ao ser como um episódio exterior à narrativa da história. Modelam-lhe, e modulam-lhe, desde o entranhado âmago da sua imanência, a trajectória humanizante e os trajectos humanizados do devir.

Ao contrário do que imediatamente parece, e com frequência teorizado aparece, educação e trabalho - com as especificidades reais que thes determinam o respectivo viso - encontram-se inscritos na ontologia daquela porção do ser que dispõe de forma humana. E é no rolante tapete deste horizonte ontológico que escrevem - que vão escrevendo, e inscrevendo.

Sem trabalho, não há materialmente produção do viver. O que acontece ao longo de um processo onde, de igual modo, a cultura, as ideias, o colorido da afectividade - dimensões que se educam no cultivo -, desempenham um papel que thes é próprio (e que certamente não será aquele que o idealismo, na desgarrada das suas declinações, Ihes atribui).

Fora de um marco social de relacionalidades (que trabalham, e se trabalham) - onde o ser humano inere (mesmo na sua singularidade individual, que não é de despedir liminarmente como negligenciável efeito de uma simples ilusão na óptica) -, não há de todo formação de humanidade.

Por conseguinte, é na medida em que trans-formam que trabalho e educação, na unidade de um mesmo movimento, formam.

Adentrando-me pelo enlaçado destes tabuleiros, faço saltar da berma ao caminho mais algumas provocações (desde logo, a uma exercitação crítica do pensar).

\section{§ 3. Trabalho.}


Issn: 1808 - 799X

ano 13, número $20-2015$

O trabalho opera, antes do mais, na Natureza, e sobre a Natureza ${ }^{5}$.

Mas importa interrogar também a natureza do trabalho.

O cuidado na procura de um estabelecimento correcto dos problemas é ocupação imprescindível quando se elaboram os questionários chamados a comandar o curso da pesquisa.

Para pôr em destaque a fundamentalidade do sentido que pretendo surpreender naquele trabalho que é próprio da educação, teremos que abstrair, por um momento, de algumas das molduras em que predominantemente ele nos surge representado.

Passo a indicar, abreviadamente, três de entre elas.

Como enquadramento, permitem detectar dimensões marcantes do fenómeno. Absolutizadas, prestam-se, porém, a contaminações perturbadoras, que acabam por lhe ofuscar a concreção.

Assim, o trabalho é, mas não é «apenas», a produção material de artefactos, dotados de uma directa utilidade económica: imediata (como simples valor de uso), ou mediata (por entrada numa esfera de circulação enquanto valores de troca $)^{6}$. A tendência para a mercadorização universal de todos os bens

5 Este encaixamento, bem como a reversibilidade que nesta operação se verifica, constituem dimensões fundamentais, por cujo comentário não posso todavia enveredar aqui: «O processo de trabalho é, antes do mais, um processo entre o ser humano e a Natureza, um processo em que o ser humano, pela sua acção própria, medeia, regula, e controla, a sua troca material [Stoffwechsel] com a Natureza. O ser humano enfrenta o próprio material de Natureza [Naturstoff] como um poder de Natureza [Naturmacht]. Ele põe em movimento as forças de Natureza [Naturkräfte] que pertencem à sua corporalidade (braços e pernas, cabeça e mão) para se assimilar o material de Natureza numa forma utilizável para a sua vida própria. Ao operar, por este movimento, sobre a Natureza fora dele, e ao alterá-la, ele altera, simultaneamente, a sua natureza própria.» - «Der Arbeitsprozeß ist zunächst ein Prozeß zwischen dem Menschen und der Natur, ein Prozeß, worin er seinen Stoffwechsel mit der Natur durch seine eigne That vermittelt, regelt und kontrolirt. Der Mensch tritt dem Naturstoff selbst als eine Naturmacht gegenüber. Die seiner Leiblichkeit angehörigen Naturkräfte, Arme und Beine, Kopf und Hand, setzt er in Bewegung, um sich den Naturstoff in einer für sein eignes Leben brauchbaren Form zu assimiliren. Indem er durch diese Bewegung auf die Natur außer inm wirkt und sie verändert, verändert er zugleich seine eigne Natur.», MARX, Das Kapital. Kritik der politischen Ökonomie. Erster Band. Hamburg 1867, I, 3, 1; MEGA $^{2}$, vol. II/5, p. 129.

6 Como curiosidade, refira-se que, muito antes da famosa distinção smithiana entre value in use e value in exchange - cf. Adam SMITH, An Inquiry into the Nature and Causes of the Wealth of Nations (1776), I, IV; ed. William Letwin (doravante: WN), London - New York, J. M. Dent \& Sons -

TrabalhoNecessário - www.uff.br/trabalhonecessario; Ano 13, No 20/2015. 
Issn: 1808 - 799X

ano 13, número $20-2015$

e serviços é inerente ao capitalismo, mas não é forçoso que todo o trabalho só seja trabalho, na estrita (e estreita) medida em que obedeça aos parâmetros que regem a fabricação de mercadorias.

Ademais, na cercadura de um modo capitalista de produção - como, de resto, em outras formações económicas da sociedade, que assentam no apossamento por alguns (poucos) do sobretrabalho de outros (muitos) ${ }^{7}-$, as diferentes modalidades de trabalho alienado imperam. É trabalho alienado que está na origem da propriedade privada, e a propriedade privada dos meios de produção estrutura, por sua vez, as relações sociais em que a apropriação do trabalho de outrem se realiza ${ }^{8}$. Mas não é todavia fatal que a «alienação» constitua a sina inescapável de todo e qualquer trabalho.

E. P. Dutton \& Co. (Everyman's Library), 1975², vol. I, pp. 24-25 -, já Aristóteles havia assinalado

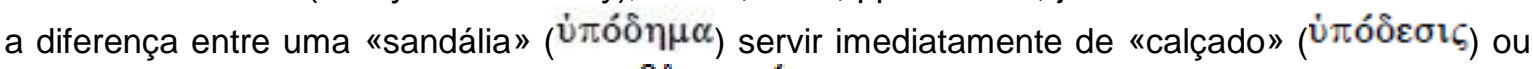

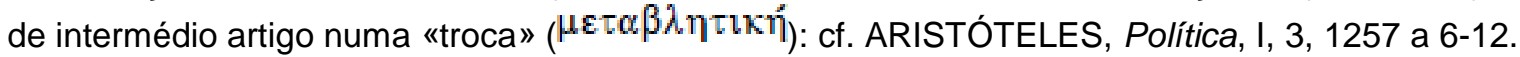

7 «Não foi o capital [...] que inventou o sobretrabalho. Em qualquer lugar onde uma parte da sociedade possui o monopólio dos meios de produção, o operário, livre ou não-livre, tem que acrescentar tempo de trabalho excedentário ao tempo de trabalho necessário para a sua autoconservação, de modo a produzir os meios de vida para os donos dos meios de produção,

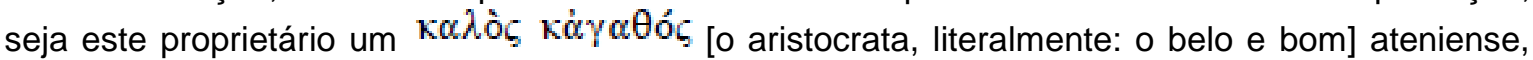
um teocrata etrusco, [um] civis romanus [cidadão romano], [um] barão normando, [um] dono de escravos [Sklavenhalter] americano, [um] boiardo valáquio, [um] landlord [senhor da terra] moderno, ou [um] capitalista.» - «Das Kapital [...] hat die Mehrarbeit nicht erfunden. Ueberall, wo ein Theil der Gesellschaft das Monopol der Produktionsmittel besitzt, muß der Arbeiter, frei oder unfrei, der zu seiner Selbsterhaltung nothwendigen Arbeitszeit überschüssige Arbeitszeit zusetzen, um die Lebensmittel für die Eigner der Produktionsmittel zu produziren, ob dieser Eigenthümer nun ein atheniensischer $\kappa \alpha \lambda$ ò $\zeta \kappa \dot{\alpha} \gamma \alpha \theta$ ó $\zeta$, ein etruskischer Theokrat, civis romanus, normännischer Baron, amerikanischer Sklavenhalter, walachischer Bojar, moderner Landlord oder Kapitalist ist.», MARX, Das Kapital. Kritik der politischen Ökonomie. Erster Band. Hamburg 1867, I, 3, 4; MEGA², vol. II/5, p. 181.

8 Cf. MARX, Ökonomisch-philosophische Manuskripte (1844), Heft I, Entfremdete Arbeit und Privateigentum; MEGA2, vol. I/2, pp. 363-375. Enriquecido por significativos desenvolvimentos no que diz respeito à penetração do "segredo" da mais-valia (chave para o aclaramento da exploração), o tema - inclusivamente, com recurso explícito ao léxico da "alienação" (Entfremdung, Entäusserung) - continua presente em muitos textos posteriores (ao invés do que, por vezes, se ouve repetido). Cf., por exemplo, MARX, Ökonomische Manuskripte 1857/58, Grundrisse der Kritik der politischen Ökonomie. Erster Teil, III, Arbeitsprozeß und Verwertungsprozeß (MEGA2, vol. II/1.1, p. 239) ou Das Kapital. Kritik der politischen Ökonomie. Dritter Band. Hamburg 1894, III, I, I, 5, I (MEGA², vol. II/15, p. 85).

TrabalhoNecessário - www.uff.br/trabalhonecessario; Ano 13, N²0/2015. 
Issn: 1808 - 799X

ano 13, número $20-2015$

Do mesmo modo, quando se submete a exame a questão do carácter «produtivo» ou «improdutivo» de um dado trabalho, convém não perder de vista o regime histórico concretamente determinado em que essa diferença é chamada a funcionar. Porque aquilo que nela em causa está não é a determinação material intrínseca do trabalho, mas a forma social determinada dentro da qual ele se exerce. Naquela ordem que ao capitalismo corresponde, apenas é «produtivo» aquele trabalho que produz mais-valia apropriável pelo capitalista9 ${ }^{9}$.

Ou como Marx, neste contexto do capitalismo, e a propósito de um esclarecedor exemplo, observa: «Um escritor é um operário produtivo [ein produktiver Arbeiter], não na medida em que ele produz ideias, mas na medida em que ele enriquece o livreiro que explora a edição dos seus escritos, ou na medida em que ele é o assalariado de um capitalista.» ${ }^{10}$.

9 Para o fisiocratismo setecentista, num contexto em que a terra é o reconhecido meio de produção hegemónico, só são produtivas as despesas que se reportam directamente à agricultura, enquanto aquelas que se fazem «em mercadorias de mão d'obra» (en marchandises de main d'oeuvre) são classificadas de «estéreis» (stériles). Cf. François QUESNAY, Tableau économique (1758-1759), Explication du Tableau économique; Physiocratie. Droit naturel, Tableau économique et autres textes, ed. Jean Cartelier, Paris, Flammarion, 1991, p. 91. Para Adam Smith, que pensa condições económicas que entretanto em Inglaterra amadureceram, produtivo é somente aquele trabalho que "acrescenta valor» (adds value) ao produto, e daí a privilegiada exemplaridade conferida à indústria manufactureira. Cf. SMITH, An Inquiry into the Nature and Causes of the Wealth of Nations (1776), II, III; WN, vol. I, pp. 294-312. Tanto a um como ao outro escapa o fundamental que no modo capitalista de produção ocorre: "Trabalho produtivo, no sentido da produção capitalista, é o trabalho assalariado que, na troca contra a parte variável do capital (a parte do capital desembolsada em salário), não apenas reproduz essa parte do capital (ou o valor da sua faculdade de trabalho própria), mas, além disso, produz mais-valia para o capitalista. Só por esse facto mercadoria ou dinheiro são transformados em capital, produzidos como capital. Só é produtivo o trabalho assalariado que produz capital.» - «Produktive Arbeit im Sinn der kapitalistischen Produktion ist die Lohnarbeit, die im Austausch gegen den variablen Teil des Kapitals (den in Salair ausgelegten Teil des Kapitals) nicht nur diesen Teil des Kapitals reproduziert (oder den Wert ihres eignen Arbeitsvermögens), sondern außerdem Mehrwert für den Kapitalisten produziert. Nur dadurch wird Ware oder Geld in Kapital verwandelt, als Kapital produziert. Nur die Lohnarbeit ist produktiv, die Kapital produziert.», MARX, Theorien über den Mehrwert, I, 4, 1; Marx - Engels Werke, ed. IML (doravante: MEW), Berlin, Dietz Verlag, 1976, vol. 26.1, p. 122.

10 «Ein Schriftsteller ist ein produktiver Arbeiter, nicht insofern er Ideen produziert, sondern insofern er den Buchhändler bereichert, der den Verlag seiner Schriften betreibt, oder sofern er der Lohnarbeiter eines Kapitalisten ist.», MARX, Theorien über den Mehrwert, I, 4, 3, a; MEW, vol. 26.1, p. 128.

TrabalhoNecessário - www.uff.br/trabalhonecessario; Ano 13, N²0/2015. 


\section{Trabalhonecessário}

Issn: 1808 - 799X

ano 13, número $20-2015$

Os aspectos que acabamos de esboçar em apontamento integram aquilo que Marx, nos Manuscritos de 1844, designa por «o lado negativo» (die negative Seite) do trabalho ${ }^{11}$. Resultam de modos determinados de organizar socialmente a produção, com as relações de exploração que lhes correspondem.

Não obstante, sob esta casca de desfiguramentos, encontra-se, e pulsa, também um núcleo «positivo» de actividade. Sobre o qual, designadamente, haverá que edificar um regime de produção, e relações produtivas, à altura dos anseios, das exigências e das possibilidades reais, de um estádio de desenvolvimento mais rico e omnilateral, próprio de uma humanidade emancipada.

O trabalho, pela sua natureza constitutiva, é um processo de transformação. Pro-duz, porque faz advir (pondo-nos diante) formas (não necessariamente reificadas na função de «mercadoria») que alteram (fazem assumir uma figura outra) um dado estado prévio de elementos disponíveis (porque toda a criação tem condições que começa por instalar, não se faz a partir de nada).

Acolhido, tomado, e visto, nesta radicalidade de estrutura, o trabalho - tal como a prática, ou como qualquer processo criativo - tece-se e entretece-se de «negatividade» formadora. Opera como trans-gressão de uma positividade existencialmente dada, e como engendramento de configurações anteriormente não advindas.

À luz do sentido que esta atitude ex-põe: a educação é um trabalho do ser na sua figura humana.

O que nos leva até uma outra estação do nosso percurso.

\section{§ 4. Função e paradigmas.}

11 Cf. MARX, Ökonomisch-philosophische Manuskripte (1844), Heft III, Ergänzungen zu Heft II, Kritik der Hegelschen Dialektik und Philosophie überhaupt; MEGA², vol. I/2, p. 405. 


\section{Trabalhonecessário}

Issn: 1808 - 799X

ano 13, número $20-2015$

Podemos estar sozinhos numa ilha. Podemos sentir-nos na solidão insularizados. Podemos saborear na fruição co-respondida a con-vivência do outro. Podemos debater-nos na angústia, como Jean-Paul Sartre, porque afinal «o inferno... é os outros» ${ }^{12}$.

Em qualquer caso - segundo modalidades diferentes de presença (e de ausência) -, somos sempre a própria singularidade que vamos sendo, no horizonte de uma retorsa trama de relacionamentos.

E toda a existência societária dos humanos está entrecruzada por dispositivos - formalizados, e informais - de educação. Desde a nocturna conversa de tribo ao redor de uma fogueira, até ao mais sofisticado instituto de pesquisas avançadas.

Actuando num mundo que nos con-fronta e interpela, é de dentro de uma troca de experiências - directa, e indirecta, no limite: consolidadas numa cultura, enquanto sedimentação do testemunho pensado de outros - que, como expressão humana do ser, nos formamos, re-formamos, e trans-formamos.

Numa continuidade em deveniência, que não é unilinear, nem automática, mas conturbadamente dialéctica: nas curvas, contracurvas, e recurvos.

O cuidado social pela função educativa não revestiu porém sempre as mesmas formas, nem obedece, no corte e na costura, a uma unicidade de figurinos orientadores.

Nas praças da vizinhança, conhecem-se, no entanto, alguns modelos recorrentes, que, com adaptações, são adoptados pelos adeptos.

Lembro, telegraficamente e de modo impressionista, uns quantos.

O paradigma (translatício) da baldeação, ou o transbordo pedagógico de cargas. Das cafurnas (empanturradas) do porão da urca dos «sabentes», transferem-se, para o tombadilho (desimpedido) da barcaça dos «noviços», as

12 «Não é preciso grelha: o inferno... é os Outros.» - «Pas besoin de gril: l'enfer, c'est les Autres», Jean-Paul SARTRE, Huis clos (1944), V; Huis clos suivi de Les Mouches, Paris, Éditions Gallimard, 1947, p. 75.

TrabalhoNecessário - www.uff.br/trabalhonecessario; Ano 13, No 20/2015. 


\section{Trabalhonecessário}

Issn: 1808 - 799X

ano 13, número $20-2015$

preciosas especiarias e pesados fardos, que, através de obediente esforço mnésico, Ihes competirá reter, e, em papagueio vomitório subsequente, regorgitar. Em suma, é o formato mecânico, e em embalagem cartonada, das trans-missões de um «património» - intocado, e intocável.

Este usado veículo do transporte escolar também está disponível na variante do paradigma charcuteiro. A «educação» mascara-se de febril «linha de montagem», e o «educando» vira tripa elástica para acondicionar o embutido das linguiças. Algumas avariações (exaltadas) de "cognitivismo» (exacerbado) dão sinais de propender a uma certa perfilhação deste expediente fabril no ensacamento de carnes.

O paradigma (circense) dos animais amestrados. Combina a férrea disciplina do macaqueio de tiques e de toques, com a pequena exibição de algumas «habilidades» em berloque, e o honrado quadradinho de açúcar ao final do número. $\mathrm{O}$ aparente resultado em vista é a confecção de estereótipos dóceis, bem afeiçoados ao molde que o domador prescreve, e que certas plateias (deliradas) ovacionam. Faz-me lembrar aquela trupe de canídeos aos pulinhos pela pista, passeando uns trajes de andaluza e de toureiro.

O paradigma (complementar) do gato maltês. Que tocava piano e falava francês. Uma delícia caseira para os pasmados e visitas. Como há que acompanhar o evoluir das modas, introduziram-se uns arranjos. Agora é: que percute furiosamente os desconsolos no teclado da consola, e que arranha uns miados de inglês.

E, claro está, da trouxa do enxoval - soletrado nas solfas da cartilha liberalista achicagada -, vemos também empertigar-se o paradigma do negócio. Tem por suposto remoto a mercadorização da actividade educativa, convertida em «artigo» de compra e venda com que se acena à clientela dos fregueses.

No quadro (instalado) da mundialização (instilada) - sob a imperial pilotagem com rosto do Fundo Monetário Internacional, da Organização Mundial do Comércio, do Banco Mundial, e das suas sucursais na região e no bairro -, 


\section{Trabalhonecessário}

Issn: 1808 - 799X

ano 13, número $20-2015$

recrudescem, na violência e no tom, as ofensivas orquestradas contra a Escola Pública. Visam um retrocesso no desenho das políticas, e o pastoreio domesticado da consciência dos rebanhos.

$\mathrm{Na}$ ordem interna dos Estados - onde, ao cabo de brava luta, sistemas nacionais de ensino estão consolidados (pela cobertura que proporcionam), e desempenham um papel preponderante (pela qualidade de que se revestem) -, aceleram a marcha as mais desvairadas operações de asfixia e de desmantelamento. E fomenta-se - com bastante denodo, e pouca vergonha uma curiosa trasfega de líquidos em cheque: da bolsa de fundos públicos que os impostos (de quem trabalha) alimentam, para o bolso privado (sem fundo) dos arrendadores do «serviço» em subempreitada.

Atentos estes (e outros) panoramas ajardinados que nos pintam e impingem, há, de facto, muito trabalho a colectivamente fazer pela educação. Pelo vitalizar da natureza (e da responsabilidade) intrinsecamente social da educação. Pela tomada a cargo cidadã do seu funcionamento efectivo enquanto um dos pilares da soberania.

Leigo como sou (e avisei que era), não consigo delinear programas de redenção milagrosa, nem conheço receitas de infalível sucesso. Apenas vos posso estender um pobre material em tosco. Que talvez ajude a pensar o trabalho da educação.

Transitemos, pois, ao remate desta fala.

Sem anúncios - nem promessas - de um final apoteótico.

\section{§ 5. O trabalho da educação.}

O que trago para vos dizer é escasso, é confrangedoramente pouco. Abundante, desmesuradamente muito, é tudo aquilo que continua a desafiar-nos o fazer. 


\section{Trabalhonecessário}

Issn: 1808 - 799X

ano 13, número $20-2015$

A educação é um processo de desenvolvimento.

É - objectiva, e subjectivamente - um trabalho: porque forma, e transforma, seres humanos.

É, nas vicissitudes com peripécia, uma viagem: que se desenrola num horizonte, comungado, de emancipação.

Cuidado, por isso, com certas compartimentações precipitadas. Que arrumam, mais do que esclarecem.

Há quem imagine "a Educação» como uma espécie de ginásio, um simulador para treino de outros voos, uma antecâmara de espera. Seria a «preparação» para uma «vida»... a vir depois.

Como se o espaço educativo não fosse o tempo de um viver!

Como se os tempos da vida não fossem o espaço da educação!

Como se antepostas doses de atormentada «preocupação» dispensassem a dureza e o durar da ocupação!

Educar é eduzir: trazer para fora e para a frente. Não como soltura de um tesouro infuso que, encarcerado nos recônditos de uma interioridade imaculada e selvagem, aí se encontrasse em estado de adormecida latência, pronto a despertar ao toque da varinha mágica. Mas como libertação - relativamente ao muito que nos enreda e dissuade - para a aventura de compreender e de reconfigurar tudo aquilo que diante (em espectáculo), e adiante (em feitura), enriquecidamente se oferece.

A educação devém, nestes termos, o processo relacional aberto (onde a instância do diálogo, e a circunstância do educador, são marcantes), pelo qual, operando toda uma descoberta conjunta do mundo e da vida (e, por isso, é preciso ir sabendo coisas), vamos dando forma à condução do nosso viver.

Penso que é em torno deste eixo que o decisivo gira. Mesmo quando a atenção, de ordinário, noutras componentes está focada.

A «autoridade» - consentida, e com sentido - parece jogar uma cartada em certos procedimentos educativos. Mas, na educação, aquilo que de 


\section{Trabalhonecessário}

Issn: 1808 - 799X

ano 13, número 20 - 2015

fundamental se joga - numa pluralidade de sentidos - é um profundo modelar da autoria.

Mais do que sermos educados - numa por vezes imaginária relação de apetecida passividade -, nós todos nos educamos (mesmo quando por isso não damos, e para isso julgamos não estar a contribuir). Numa complexa (e contraditória) convivialidade com os outros.

Tremenda responsabilidade. Não pelas «culpas» eventuais que alguém, algum dia, nos possa contabilizar. Mas pelos respondimentos efectivos que vamos dando, neste nosso quotidiano, e tão desleixado, ofício do viver.

A educação só devém património que se possui, só nos pertence, porque in-siste num acto de reiterada apropriação (e de partilha) que se distende.

O processo ontogenético de hominização é, do mesmo passo, um acidentado - e, para já, inconcluso - percurso histórico de humanização.

Nas contexturas do mundo, e nos entretextos da socialidade, a figura humana do ser faz-se: fazendo, e fazendo-se. No cultivo de uma fazenda: a inscrição daquele cunho de humanidade que protagoniza no corpo deveniente das realidades que integra, de cuja mediação é agente, e que transforma.

A educação re-produz, porque reflecte, e refracta.

Con-duz, porque acompanha, e guia.

Mas também pro-duz, porque suscita ao fronteiro horizontes de por vir.

Daí o acentuado relevo a pôr na perscrutação crítica dos fundamentos daquilo que, inquestionado, na sua imediatez se impõe.

Daí o vigilante cuidado a dispensar à colocação correcta dos problemas que, a cada cavadela, nos defrontam.

Daí o imprescindível afinamento a empreender de uma sensibilidade aberta ao detectar das possibilidades reais que nos desafiam a materialização.

Somos - na própria historicidade que nos empapa o ser - em desequilibração ao futuro. Que é um feituro. Um a-fazer por fazer. 


\section{Trabalhonecessário}

Issn: 1808 - 799X

ano 13 , número $20-2015$

E, neste transe, na perspectivação dos trânsitos, a racionalidade - que se demanda, e exercita - irrompe, e rompe.

Compreender, para transformar. Transformar, compreendendo.

Talvez seja esta a dialéctica, materialmente fundada, que do fundo do trabalho da educação nos con-cita a todos.

Há um velho fragmento de Heraclito de Éfeso que, nestas tarefas e viandâncias, quadra, porque as enquadra:

«Quem não espera, não encontrará o inesperado, porque ele é inencontrável e inacessível.»13.

Soa bem, mas não é fácil.

Porque não traduz uma encomendação resignada aos braços cruzados da espera.

Vibra, outrossim, como um lúcido (e sempre renovado) convite ao trabalhar da esperança.

O que, saltando confiante do peito para uma outra morada nos quotidianos da história, nos remete ao confiado engendramento solidário daquelas condições materiais (objectivas, e subjectivas) que Ihe promovam a eclosão. Um processo do qual, aliás, as lutas com prospecto não se encontram de todo higienicamente arredadas.

Muito obrigado pela vossa paciência.

Lisboa, Julho de 2014.

Recebido em 10 de setembro de 2014

Aprovado em 25 de outubro de 2014

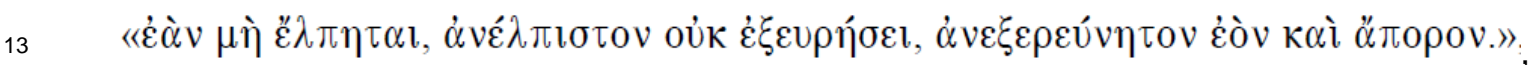
HERACLITO, Fragmento B 18; Die Fragmente der Vorsokratiker, ed. Hermann Diels e Walther Kranz, Berlin, Weidmannsche Verlagsbuchhandlung, 1956², vol. I, p. 155. 